\title{
Farbenindustrie durch Entwicklung an Rohstoffmärkten unter Druck
}

\author{
Die europäische Lack-, Druckfarben- und Künstlerfarbenindustrie steht aufgrund steigender \\ Rohstoffpreise unter hohem Druck. Ein komplexer Mix aus Nachfrage, Kapazitätsproblemen und \\ knappen Transportressourcen erhöht bei wichtigen Rohstoffen die Unsicherheit in der Lieferkette.
}

Nach einem Jahr, das von der COVID19-Pandemie geprägt war, steht die Farbenindustrie 2021 aufgrund der steigenden Rohstoffpreise erneut vor großen Herausforderungen. Für den Anstieg gibt es mehrere Gründe: eine erhöhte Nachfrage nach Rohstoffen durch die erwartete wirtschaftliche Erholung, eine Verknappung der verfügbaren Rohstoffe wegen schlechter Wetterbedingungen sowie die Schließung mehrerer Werke, die Rohstofflieferanten sich auf force majeure - also höhere Gewalt - berufen lässt. Zusätzlich erhöhen sich die Transportkosten durch den stark gestiegenen Ölpreis.

\section{Das sind die Kostentreiber}

„Die Belastung für die Branche ist immens, da die Rohstoffpreise mehr als die Hälfte der Kosten ausmachen“, so André Vieira de Castro, Vorsitzender des Verbandes der europäischen Lack-, Druckfarben- und Künstlerfarbenindustrie (CEPE). Seit Januar sind die Kosten für Schlüsselkomponenten wie Epoxidharze in Europa um 60 \% gestiegen. Ähnlich sieht es bei den Lösemitteln aus,

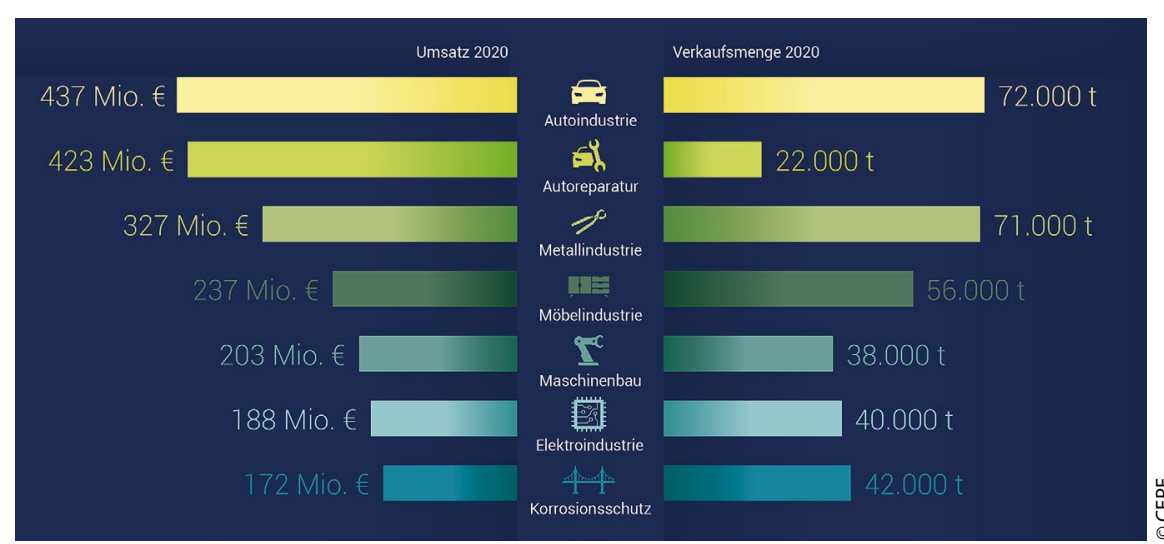

Lacke für industrielle Anwendungen in Deutschland: In den größten sieben Abnehmerbranchen wurden 2020 auf dem deutschen Markt 341.000 Tonnen Lacke im Wert von zwei Mrd. Euro verkauft.

allein der Preis für Aceton und n-Butylacetat ist dort um $123 \%$ beziehungsweise $91 \%$ gestiegen. Die aktuelle Situation hat ihren Ursprung in Europa und Asien, insbesondere aus der unerwartet schnellen V-förmigen Erholung in China, die die Nachfrage nach wichtigen Rohstoffen anheizt. Neben Epoxidharzen umfasst die Liste der stark nachgefragten petrochemischen Rohstoffe unter anderem Polyesterharze, Polypropylenglykole, Acrylsäuren, Acrylharz, UV-Harze, Polyurethanharze und Lösungsmittel. Parallel zu den petrochemischen Rohstoffen sind auch die globalen Kosten für Pigmente (einschließlich Titandioxid, rotes und gelbes Eisenoxid) stark gestiegen. $\mathrm{Zu}$ den wichtigsten Treibern der Preiserhöhungen gehören die starke Nachfrage in allen Industriebereichen, ein größerer inländischer Versorgungsbedarf in den Produktionsländern, allgemeine Ungleichgewichte zwischen Angebot und Nachfrage sowie höhere Kosten für Pigmentkomponenten. Die aktuelle Situation wird durch Kapazitätsprobleme zusätzlich verschärft: Störungen bei Produzenten in Asien und Europa - entweder durch Fabrikschlie- 